\title{
Distribution Patterns of Extracellular Matrix Components and Adhesion Receptors Are Intricately Modulated during First Trimester Cytotrophoblast Differentiation along the Invasive Pathway, In Vivo
}

\author{
Caroline H. Damsky, ${ }^{\star *}$ Marilyn L. Fitzgerald, * and Susan J. Fisher**s4 \\ Departments of *Stomatology, ${ }^{\ddagger}$ Anatomy, ${ }^{\S}$ Pharmaceutical Chemistry, and 'Obstetrics, Gynecology, and \\ Reproductive Sciences, University of California San Francisco, San Francisco, California 94143
}

\begin{abstract}
Development of the human embryo depends on the ability of first trimester cytotrophoblastic stem cells to differentiate and invade the uterus. In this process, transient expression of an invasive phenotype is part of normal cytotrophoblast differentiation. Morphologically, this process begins when polarized chorionic villus cytotrophoblasts form multilayered columns of nonpolarized cells, and invade the uterus. Using immunocytochemistry, we compared the presence of adhesion receptors and extracellular matrix ligands on cytotrophoblasts in villi, cell columns, and the uterine wall. Villus cytotrophoblasts, anchored to basement membrane, stained for $\alpha 6$ and $\beta 4$ integrin subunits and both merosin and A-chain-containing laminin. Nonpolarized cytotrophoblasts in columns expressed primarily $\alpha 5$ and $\beta 1$ integrin subunits and a fibronectin-rich matrix. Cytotrophoblast clusters in the uterine wall stained for $\alpha 1, \alpha 5$, and $\beta 1$ integrins, but not for most extracellular matrix antigens, suggesting that they interact primarily with maternal cells and matrices. Tenascin staining was restricted to stroma at sites of transition in cytotrophoblast morphology, suggesting that tenascin influences cytotrophoblast differentiation. Our results suggest that regulation of adhesion molecule expression contributes to acquisition of an invasive phenotype by cytotrophoblasts and provide a foundation for studying pathological conditions in which insufficient or excessive trophoblast invasion occurs, such as preeclampsia or choriocarcinoma. (J. Clin. Invest. 1992. 89:210-222.) Key words: placenta $\bullet$ fetal-maternal interface • integrins • laminin • fibronectin
\end{abstract}

\section{Introduction}

The process by which an epithelial cell acquires an invasive phenotype is complex and difficult to study in vivo. In the adult, such transitions are usually observed retrospectively, as tumors. During embryonic development, however, certain cells exhibit invasive behavior as a normal part of their differentiation program. The trophoblastic stem cell of the placenta, the cytotrophoblast (CTB) ${ }^{1}$, is one such cell type. CTB are

Address correspondence to Dr. Caroline H. Damsky, HSW 604, University of California San Francisco, San Francisco, CA 94143-0512.

Received for publication 9 July 1991 and in revised form 20 September 1991.

1. Abbreviations used in this paper: $\mathrm{BM}$, basement membrane; Col IV, collagen type IV; CTB, cytotrophoblast(s); ECM, extracellular matrix;

J. Clin. Invest.

(c) The American Society for Clinical Investigation, Inc.

$0021-9738 / 92 / 01 / 0210 / 13 \$ 2.00$

Volume 89, January 1992, 210-222 highly migratory and able to invade basement membranes (BM) as well as interstitial matrices. Since the structural organization of placental tissue at the fetal-maternal interface recapitulates spatially the differentiation process by which noninvasive CTB stem cells acquire the ability to invade the uterine wall, it is an ideal tissue in which to monitor the molecular changes that take place during acquisition of an invasive phenotype. Furthermore, errors in either direction in the depth of implantation in humans result in pathologic conditions. Insufficient invasion contributes to the development of preeclampsia (1), a condition that results in fetal intrauterine growth retardation and maternal hypertension and proteinuria (2). Unrestricted invasion results in a variety of premalignant conditions (placenta accreta, hydatidiform mole) as well as choriocarcinoma. Thus, understanding factors regulating CTB invasion is critical to understanding the etiology of trophoblast-related disorders.

Two CTB differentiation pathways exist, giving rise to trophoblast populations that are morphologically and functionally distinct (3-8). In the first trimester, CTB stem cells reside in chorionic villi of two types (Fig. 1, $A$ and $B$ ). "Floating" villi (Fig. 1, $A$ and $B$; FV) do not contact the uterine wall. CTB in these villi exist exclusively as polarized epithelial monolayers, anchored to a BM and surrounding a stromal core containing fetal blood vessels. These CTB, which are highly proliferative in the first trimester of gestation, differentiate exclusively by fusing to form a syncytial layer (STB) that covers the villus. Floating villi, which comprise the fetal compartment of the placenta, are bathed by maternal blood and perform gas and nutrient exchange functions for the developing embryo.

In contrast, anchoring villi (Fig. $1, A$ and $B ; \mathrm{AV}$ ) contain CTB stem cells that enter both differentiation pathways. In much of the anchoring villus, CTB fuse to form syncytium. However, at selected sites CTB break through the syncytium and form multilayered columns of nonpolarized cells. Anchoring villi, via these cell columns, physically connect the embryo to the uterine wall and give rise to the most highly invasive and migratory CTB. These cells, also referred to as intermediate trophoblasts $(9,10)$, are found in the pregnant endometrium (decidua) and the first third of the myometrium (collectively called the placental bed), and a subpopulation invades uterine blood vessels. The process of anchoring villus formation, and associated CTB invasion of the uterine wall, is extremely active

Fn, fibronectin; FnA, Fn that includes the EIIIA alternatively spliced domain; FnB, Fn that contains the EIIIB alternatively spliced domain; 1st TM, first trimester; hPL, human placental lactogen; Ln, laminin; Ln A, Ln with standard A chain; Ln M, a Ln with an alternative A chain; $\operatorname{Ln} B 1, \mathrm{Ln}$ with the standard B1 chain; $\operatorname{Ln} \mathrm{S}, \mathrm{s}-\mathrm{Ln}$ with an alternative B1 chain; Ln B2, the B2 chain of Ln; STB, syncytiotrophoblast; Tn, tenascin. 
during the first trimester, resulting in rapid placental expansion $(10,11)$. Thus, human CTB differentiation along the invasive pathway is highly unusual in that successful penetration of the uterine wall by CTB requires that they transiently express an invasive phenotype similar to that displayed by malignant tumor cells.

Sections of a full-thickness first trimester implantation site (Fig. 1, $B$ and $C$ ) contain the fetal-maternal transition zone, which is comprised of anchoring villi, their associated cell columns and the decidualized endometrium (Fig. $1 A$, zones I-IV; see also references 9,10 ). At the interface of the villus and the cell column (zones I and II), the organization of CTB changes, from a polarized cell layer anchored on a BM to a multilayered column of coherent, nonpolarized cells. The CTB throughout the length of the column have a similar vacuolated morphology. However, results to be presented below show that column CTB have regional differences with respect to their expression of matrix components and adhesion receptors. Therefore, we have designated a proximal column region, comprised of the first few cell layers (zone II), and a distal column region (zone III). Where columns contact the uterine wall, they spread laterally and penetrate the endometrium (transition from zone III to zone IV). The column structure is then lost, and CTB within zone IV are present as clusters of irregularly shaped cells interspersed among maternal leukocytes and decidual cells of the endometrium (Fig. 1, $A$ and $C$ ). With deeper penetration the CTB clusters consist of fewer cells, and single cells are frequently seen within the myometrium.

The description above indicates that differentiating CTB undergo striking changes in their relationships with one another and with extracellular components of both fetal and maternal origin. These morphological changes are likely to involve extensive modulation in CTB expression of adhesion molecules and extracellular matrix (ECM) components. To test this hypothesis, we used an immunocytochemical approach and sections of the fetal-maternal transition region (Fig. 1, $B$ and $C$ ). Our results document that marked changes in the distribution patterns of adhesion-related molecules accompany the spatial progression of CTB from the chorionic villi to the uterine wall.

\section{Methods}

\section{Antibodies}

Markers for cytotrophoblasts. In chorionic villi and the column portion of anchoring villi, cytokeratins are the most useful markers for CTB. Anticytokeratin antibodies stain CTB and STB but not villus stromal components (7). In contrast, antibody against the hormone human placental lactogen (hPL), which is specific for differentiated trophoblasts, stain only the STB layer that surrounds villi and cell columns and distinguishes this layer from the underlying villus and column CTB (9). Within the uterine wall anti-hPL is the most useful reagent, as it reacts specifically with the differentiated CTB (also called intermediate trophoblasts) present in the placental bed (9). In contrast, anticytokeratins stain uterine epithelium as well as CTB. Polyclonal antibody against hPL was obtained from Dako Corp., Carpenteria, CA. MAb (INNhPL-37) against hPL was obtained from Serotec Ltd., Blackthorn Bicester, UK. The rat anticytokeratin MAb 7D3 was produced in this laboratory by injection of first trimester (1st TM) CTB into rats as described previously (12). Its specificity was identified by the immunofluorescence staining pattern on JAR choriocarcinoma cells and immunoblotting of JAR cell extracts (data not shown).
Antibodies against extracellular matrix components. Antibodies were obtained from the following sources: mouse MAbs specific for the A chains of $\operatorname{Ln}(4 \mathrm{C} 7$ and $11 \mathrm{D} 5 / \mathrm{C} 4)$ and of merosin $(2 \mathrm{G} 9,1 \mathrm{~F} 9 / \mathrm{G} 6)$, the B1 chain of $\operatorname{Ln}(3 E 5 / H 2 E 7)$, and the B2 chain of $\operatorname{Ln}(2 \mathrm{E} 8 / \mathrm{A} 11)$, Dr. Eva Engvall, La Jolla Cancer Foundation, La Jolla, CA (13, 14); mouse MAbs against s-laminin ( $C 4$ and $C 1$ ), an alternative $\mathrm{Ln} B 1$ subunit, and against the B2 subunit of $\operatorname{Ln}$ (D18), Dr. Joshua Sanes, Washington University, St. Louis, MO (15); polyclonal rabbit anti-mouse Ln, Deborah Hall and Louis Reichardt, UCSF, San Francisco, CA; rabbit polyclonal anti-Fn, Collaborative Research, Lexington, MA; mouse anti-Fn MAbs specific for the alternatively spliced A and B type III repeats (IST-9 and BC-1, respectively) and for a site common to all Fns (IST-4), L. Zardi, University of Genova, Italy (16); a second commonsite mouse anti-Fn MAb, Telios Pharmaceuticals, Inc., La Jolla, CA; mouse MAb against collagen type IV (Col IV) (\#M785), Dako Corp.; polyclonal anti-Col IV (\#AB748), Chemicon Intl. Inc., El Segundo, CA; mouse Mab against collagen type III, Robert Burgeson, Shriner's Hospital, Portland, OR; rabbit anti-Tn, Telios Pharmaceuticals.

Antibodies against adhesion receptors. Table I summarizes the specificities of the integrins examined in this study. Rat MAbs against the integrin $\beta 1$ (AIIB2) and $\alpha 5$ (BIIG2) subunits were produced in this laboratory $(12,17)$. A rat anti- $\alpha 6$ MAb (JIB5) not previously described was produced by the same procedures. Its specificity was verified by reciprocal immunodepletion-immunoprecipitation using J1B5 and the known anti- $\alpha 6$ monoclonal antibody GoH3 (not shown; 18). Other adhesion receptor antibodies were obtained as follows: the $\mathrm{GoH} 3$ anti$\alpha 6$ and 10G11 anti- $\alpha 2$ MAbs, Dr. Arnoud Sonnenberg, Amsterdam $(12,18,19)$; a rat MAb against the integrin $\beta 4$ subunit (439-9B), Dr. Steven Kennel, Oak Ridge National Laboratories, Oak Ridge, TN (20); a mouse anti- $\alpha 3$ MAb (VM-2), Dr. Vera Morhenn (21); a mouse anti$\alpha 1$ MAb, originally designated TS2/7 (22) and available commercially under the name ACT-T-SET, T Cell Sciences, Inc., Cambridge, MA; mouse anti- $\alpha 4$ MAbs (P4C2, P3E3), Elizabeth Wayner (23); fluorochrome-conjugated secondary antibodies that had been absorbed to reduce interspecies cross-reactivity (rhodamine- or fluorescein-conjugated goat anti-rat and -mouse, and donkey anti-rabbit), Jackson ImmunoResearch Labs., Inc., West Grove, PA.

\section{Tissue preparation and histology}

First TM placental floating villi and placental bed biopsies were obtained immediately after elective terminations and were washed in PBS containing $0.5 \mathrm{mM} \mathrm{CaCl}_{2}, \mathrm{pH} 7.2$, to remove excess blood. One fullthickness implantation site from a 10-wk placenta was obtained as a result of a therapeutic hysterectomy. This sample contained the entire transition region between the fetal and maternal compartments. For the sake of clarity, most of the figures in this paper are taken from this sample. However, at least five other samples containing either villi and attached columns, or endometrium and myometrium, were examined and found to show similar staining patterns for all the antibodies used in this study. Most tissue samples were fixed for $30-60 \mathrm{~min}$ at $4^{\circ} \mathrm{C}$ in $3 \%$ paraformaldehyde in $\mathrm{PBS} / \mathrm{CaCl}_{2}$, then washed in PBS containing $0.1 \mathrm{M}$ glycine to block remaining aldehyde groups. For histology, samples were dehydrated in ethanol and embedded in JB4 resin (Polysciences Inc., Warrington, PA). $1-\mu \mathrm{m}$ sections were stained with hematoxylin/eosin and photographed with a Nikon HFX-IIA.

For immunocytochemistry, paraformaldehyde-fixed and washed samples were embedded in OCT (Miles Scientific Div., Miles Laboratories Inc., Naperville, IL) and frozen in liquid nitrogen (7). $5-\mu \mathrm{m} \mathrm{sec-}$ tions were cut using an HR cryostat (Slee International Inc., Tiverton, RI). To select the most useful sections, every tenth one was stained with hematoxylin and eosin and areas were located that contained all the stages of CTB differentiation within the same section. These sections had the general structure diagrammed in Fig. 1 and shown histologically in Fig. 2. Neighboring sections were then stained by single or double indirect immunofluorescence to locate both an adhesion molecule and a CTB marker antigen. Unless otherwise indicated, all antibodies were incubated with sections of tissue prepared in this way. A few samples were frozen immediately without prior fixation, and frozen 

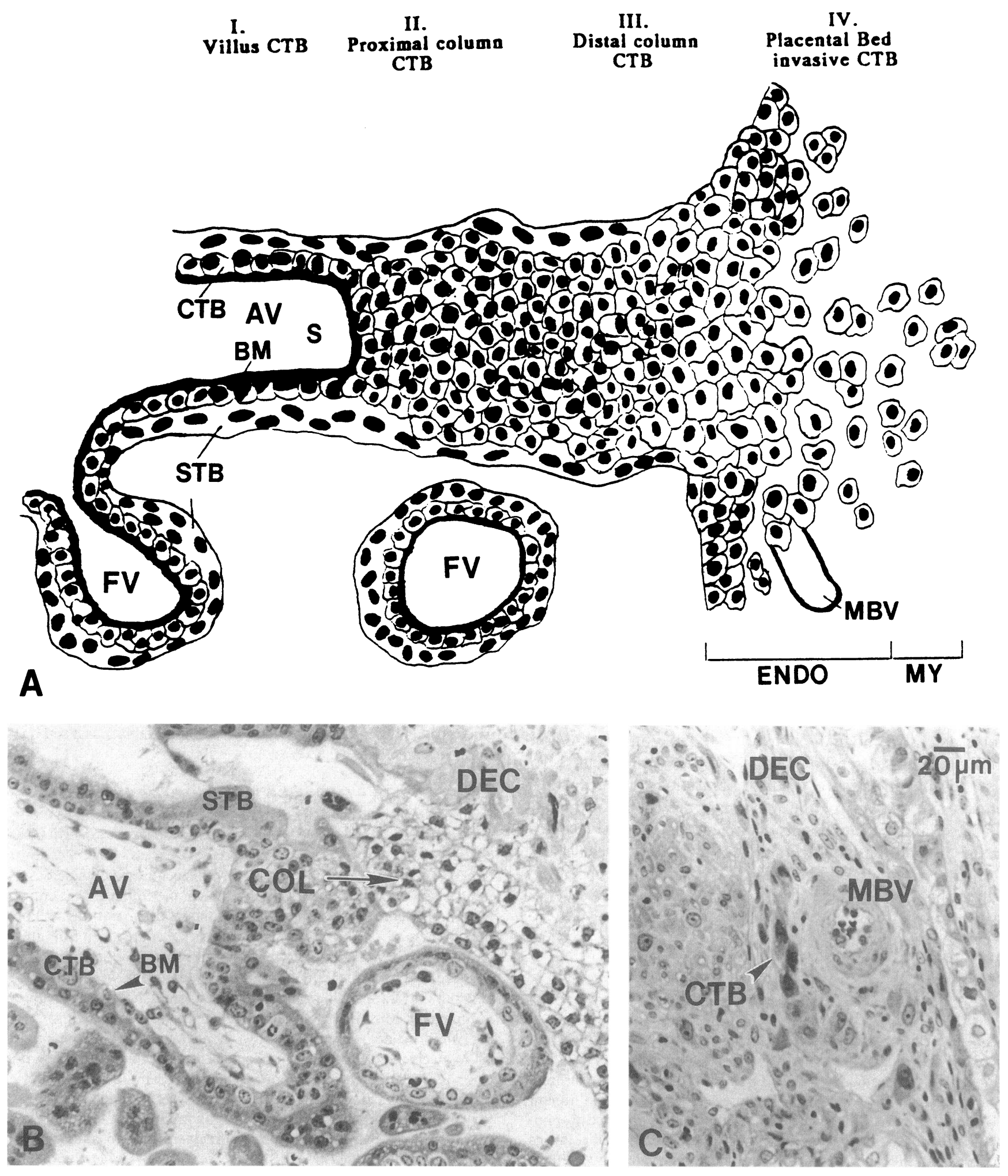

Figure 1. Organization of the fetal-maternal interface in the 10-wk human placenta. $(A)$ Diagram of the fetal-maternal interface showing floating villi $(F V)$, an anchoring villus $(A V)$ with an associated cell column, and the uterine wall. The spatial organization of this tissue (as indicated by demarcation into zones) recapitulates the differentiation of cytotrophoblasts $(C T B)$ along the invasive pathway. Most of zone I has the structure of a floating chorionic villus: mononuclear CTB stem cells, separated from the stromal core $(S)$ by a basement membrane (BM), fuse to form the overlying syncytiotrophoblast $(S T B)$ layer. However, at discrete sites in anchoring villi, CTB form a cell column that connects the fetal and maternal compartments of the placenta (zones II and III). The column spreads laterally in regions of contact with the uterine wall, and there is shallow penetration (this begins zone IV). The column then breaks up into clusters of CTB which penetrate the decidual layer and superficial myometrium $(M Y)$. The expression of adhesion and matrix components in these four zones is described in Results and summarized in Table II. MBV, maternal blood vessel; ENDO, endometrium. $(B)$ and $(C)$ Sections of a 10-wk human placental bed biopsy, embedded in JB-4 resin and stained with hematoxylin-eosin. These sections show all stages of CTB differentiation along the invasive pathway. $(B)$ Both floating and an- 
Table I. Specificities of Integrins Examined in this Study*

\begin{tabular}{ll}
\hline Integrin & \multicolumn{1}{c}{ Ligands } \\
\hline$\alpha 1 / \beta 1$ & Ln (E1 fragment) $)^{\ddagger}$, Col IV, Col I \\
$\alpha 2 / \beta 1$ & Col I, Col IV, Ln \\
$\alpha 3 / \beta 1$ & Ln (E8 fragment) $)^{\S}$ Fn, Col \\
$\alpha 4 / \beta 1$ & Fn (CS-1 domain), V-CAM \\
$\alpha 5 / \beta 1$ & Fn (RGD domain) \\
$\alpha 6 / \beta 1$ & Ln (E8 fragment) \\
$\alpha 6 / \beta 4$ & Unknown basement membrane ligand, Ln? \\
\hline
\end{tabular}

${ }^{*}(40) ;{ }^{\ddagger}(12) ;{ }^{\S}(41) ;{ }^{~}(19)$.

sections were fixed with absolute methanol at $-20^{\circ} \mathrm{C}$ before incubation with antibodies. No significant differences were found between fixed and directly frozen tissues in the staining patterns of the antibodies used for this study. However, the morphology of the paraformaldehyde-fixed material was superior.

\section{Culture and fixation of isolated CTB}

Cytotrophoblasts were isolated from 1st TM chorionic villi as described previously $(7,24)$. Cells were plated $\left(5 \times 10^{5} / 15-\mathrm{mm}\right.$ diameter well $)$ in Dulbecco's minimal essential medium containing $20 \%$ fetal bovine serum and $50 \mu \mathrm{g} / \mathrm{ml}$ gentamycin for $12-18 \mathrm{~h}$ on $11-\mathrm{mm}$ glass cover slips that had been coated for $2 \mathrm{~h}$ with a thin layer of Matrigel (Collaborative Research) or with a mixture of $\mathrm{Ln}$, Col IV, and Fn $(10 \mu \mathrm{g} / \mathrm{ml}$ each, Collaborative Research). Under these conditions, CTB form aggregates of partially spread cells. Cells were rinsed with PBS and fixed in absolute methanol for $5 \mathrm{~min}$ at $-20^{\circ} \mathrm{C}$, then air dried.

\section{Immunocytochemistry}

Frozen tissue sections or cover slips with permeabilized cells were rinsed in PBS containing $1 \mathrm{mM} \mathrm{CaCl}{ }_{2}$ and $\mathrm{MgCl}_{2}$, and nonspecific staining was blocked by incubating samples with $0.2 \%$ BSA in PBS (PBS-BSA). Samples were then exposed for $1-2 \mathrm{~h}$ to individual primary antibodies or to a mixture of two primary antibodies of different species origin, diluted in PBS. Samples were washed with several changes of PBS-BSA for $15 \mathrm{~min}$, incubated for $30 \mathrm{~min}$ with the appropriate secondary antibodies conjugated to either rhodamine isothiocyanate or fluorescein isothiocyanate, rinsed in several changes of PBS, and mounted using Gelvatol (Air Products \& Chemicals, Inc., Allentown, PA), which contained $p$-phenylenediamine (Sigma Chemical Co., St. Louis, MO) to inhibit quenching of the fluorescein signal. Normal or nonrelevant rabbit, rat, or mouse IgG were substituted for primary antibodies as controls for nonspecific staining. The staining patterns of most antibodies were tested on at least five different tissue samples. No antibody was evaluated on fewer than three samples. Samples were examined with a Zeiss phase/epifluorescence microscope equipped with the appropriate filters and a $\times 63$ planapo oil immersion objective. Sections were photographed with Kodak Tri X film, which was developed with Acufine (Acufine, Inc., Chicago, IL).

\section{Results}

Villus $C T B$ are anchored to a complex $B M$ and express primarily the $\alpha 6 / \beta 4$ integrin. The distribution patterns of ECM components and integrin receptors are considered together for each zone in the presentation and discussion of the results, which are summarized in Table II. In the villus compartment (zone I),
CTB exist as a polarized epithelial monolayer anchored to the trophoblast BM. This BM was unusual in that all the known isoforms of laminin ( $\mathrm{Ln}$ ) were detected: the $\mathrm{LnB} 2$ chain; mero$\sin$ (Fig. $2 \mathrm{~A}$ ) as well as the related $\mathrm{Ln} A$ chain (not shown); and s-laminin as well as the related Ln B1 chain (not shown; see also 14). In addition to the strong basement membrane localization of the Ln subunits detected by all the subunit antibodies, one of the anti-Ln B2 antibodies (D18) also stained the lateral and apical surfaces of villus CTB in a punctate pattern (Fig. 2 $B$ ). In the villus stroma Ln B2 staining was strong, particularly around blood vessels. The other $\mathrm{Ln}$ subunits were detected at much lower levels in the stroma, with staining for merosin (Fig. $2 A$ ) and $\mathrm{Ln} \mathrm{B} 1$ more prominent than that for $\mathrm{Ln} \mathrm{A}$ and s-laminin. Fibronectin (Fn; Fig. $2 C$ ) and Col IV (not shown) were present throughout the villus stroma and in the villus BM. Staining for both was strong in the stroma, but Fn staining of the trophoblast BM was weak, while that of Col IV was intense. Examination of Fn isoforms with domain-specific MAbs demonstrated that the Fn present contained both the A and B alternatively spliced regions.

CTB in zone I expressed a limited repertoire of integrin ECM receptors, typical of many polarized epithelia (e.g., the basal layer of the skin; 25, 26). In particular, staining of villus CTB for the $\alpha 6$ integrin subunit was strong and enriched basally (Fig. $3 A$ ). The $\alpha 6$ subunit can associate with the integrin $\beta 4$ subunit as well as with $\beta 1$ (27). A very low level of uniform $\beta 1$ staining was observed on the CTB cell surface, in addition to the prominent stromal staining (Fig. $3 \mathrm{~B}$ ). In contrast, anti- $\beta 4$ (Fig. $3 C$ ) stained the whole CTB cell surface and, like anti- $\alpha 6$ staining, was enriched basally. This suggests that $\alpha 6 / \beta 4$ was the major $\alpha 6$-containing complex expressed by villus CTB. The $\alpha 3$ integrin, which, in association with $\beta 1$, can act as a receptor for $\mathrm{Ln}$, Fn, or Col, stained CTB in $30-40 \%$ of villi weakly and uniformly (Fig. $3 D$ ). Staining for $\alpha 1 / \beta 1$, a $\mathrm{Ln}$ and Col receptor, was restricted to the villus stroma and was not detected on villus CTB (Fig. $3 E$ ). The $\alpha 5$ subunit, which when combined with $\beta 1$ is a Fn receptor, was barely detectable or not detected on villus CTB or the trophoblast BM, but was present on cells and vessels throughout the villus stroma (Fig. $3 F$ ). Thus, CTB in the villus compartment expressed primarily basally distributed $\alpha 6 / \beta 4$, and were in association with a complex Ln- and Col IV-rich BM.

$C T B$ columns are sites of extensive modulation of ECM components and integrin receptors, resulting in distal column $C T B$ with a Fn-rich ECM and high levels of the $\alpha 5 / \beta 1 ~ F n$ receptor. In the cell columns (zones II and III), CTB are no longer associated with the trophoblast BM and display a nonpolarized phenotype. These changes in their cytoarchitecture are accompanied by striking alterations in their staining patterns for ECM molecules and integrin receptors. In the proximal portion of the CTB columns (zone II), Fn and Col IV were not detected. Surprisingly, the spatial distribution of individual Ln subunits differed in this region. Merosin (Fig. $4 A$ ) and s-laminin (not shown) were not detected on column CTB, whereas the B1 subunits (not shown) and Ln B2 (Fig. $4 \mathrm{~B}$ ) were present. Two antibodies against each subunit were used, and gave the same results. In contrast, Ln A was detected by the

choring villi are shown. The stroma is separated from the overlying CTB layer by a basement membrane. A column $(C O L)$ emanating from an anchoring villus is shown spreading over the endometrial surface and penetrating the superficial decidua $(D E C)$. (C) A section deeper in the decidual layer showing a small cluster of CTB (arrow) near a maternal blood vessel. 

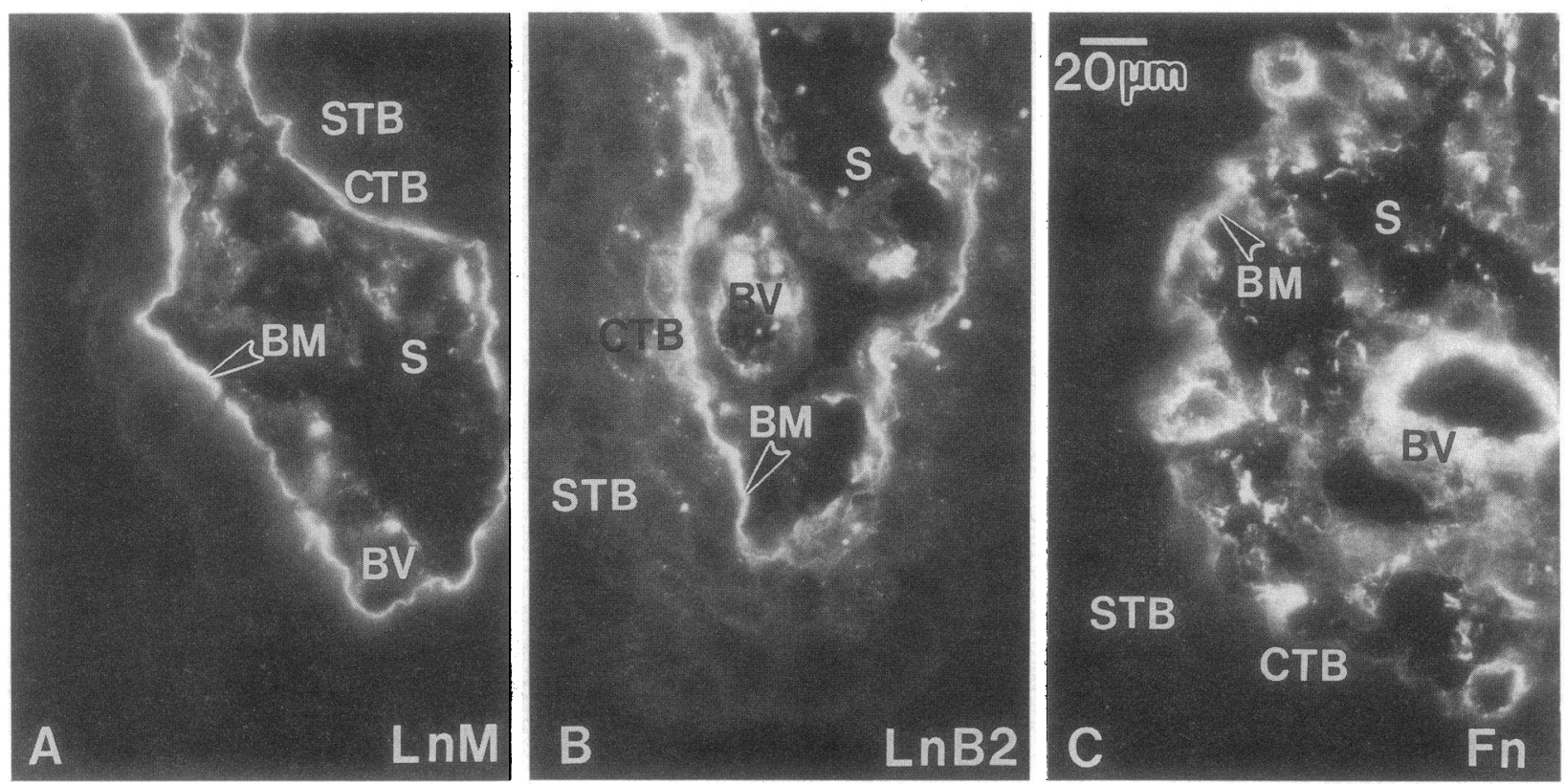

Figure 2. Frozen sections of first trimester floating villus stained for $\mathrm{Ln}$ and Fn. In this and all subsequent figures, unless otherwise indicated by use of the specific antibody identification number, all antibodies that recognize a particular antigen gave the same staining pattern. $(A)$ Antimerosin $(\operatorname{Ln} M)$ stained the trophoblast basement membrane $(B M)$, the villus stroma $(S)$, and the fetal blood vessels $(B V)$. Antibodies specific for the Ln A, Ln B1, and s-laminin subunits showed a similar staining pattern, although stroma and blood vessel staining was much weaker. $(B)$ Both of the anti-Ln B2 MAbs stained trophoblast BM and fetal blood vessels strongly. In addition, the Ln B2 MAb D18 stained the lateral borders of the CTB in a punctate pattern. $(C)$ Staining pattern of an antibody specific for the EIIIA alternatively spliced domain of Fn. Staining was strong throughout the villus stroma $(S)$, including fetal blood vessels $(B V)$. Weaker staining was also evident on the BM (arrow). Similar patterns were observed with antibodies specific for the EIIIB alternatively spliced domain and for two different sites common to all forms of Fn.

11D5/C4 monoclonal antibody, but not by the 4C7 monoclonal antibody (not shown), even though both of these antibodies stained the trophoblast basement membrane in floating villi. Thus, the presence of $\operatorname{Ln} A$ on column CTB is not clear cut at present and must wait further investigation. The staining patterns of all the anti-Ln-subunit antibodies were the same on both paraformaldehyde-fixed and frozen, methanol-fixed samples (not shown). Thus the absence of staining for merosin or s-laminin in the column region of the tissue, as well as the ambiguity in the Ln A staining, was not likely to be due to the masking of a particular epitope, or to inactivation of an epitope by aldehyde fixation. The $\alpha 3$ integrin subunit, present on some villus CTB, was no longer detected in the proximal column (not shown) and remained undetected on CTB in subsequent zones (Table II). Staining for the $\alpha 6$ and $\beta 4$ subunits continued to be strong in zone II, while $\alpha 5$ and $\beta 1$ were barely detectable (Table II).

In the distal portion of the column (zone III), several distinct changes in matrix and adhesion molecule staining patterns were evident, although the morphology of the cells did not change dramatically (Figs. 4-5). First, there was a sharp increase in the level of staining of both $\mathrm{A}^{+} \mathrm{B}^{+} \mathrm{Fn}$ and $\mathrm{Col}$ IV (Fig. 4, $C$ and $D$ ). These ECM components were likely made by the CTB, as there are no other cell types in columns. Further-

Table II. Detection of ECM Components and Integrin Receptors on Cytotrophoblasts in First Trimester Placenta

\begin{tabular}{|c|c|c|c|c|c|c|}
\hline \multirow[b]{2}{*}{ Zone } & \multirow[b]{2}{*}{ Compartment } & \multirow[b]{2}{*}{ Cell type } & \multicolumn{3}{|c|}{ Putative integrin receptors for } & \multirow[b]{2}{*}{ ECM ligands } \\
\hline & & & Ln & Fn & Col IV & \\
\hline I & Villus & CTB & $\begin{array}{l}\alpha 6 / \beta 4^{* \ddagger} \\
(\alpha 3 / \beta 1)\end{array}$ & $(\alpha 3 / \beta 1)$ & $(\alpha 3 / \beta 1)$ & $\begin{array}{l}\operatorname{Ln} A^{\xi *}, \operatorname{Ln} M^{\xi *}, \operatorname{Ln} B 1^{\xi *} \\
\operatorname{Ln} S^{\delta *}, \operatorname{Ln} B 2, \text { Fn }(A+B+)^{*} \\
\text { Col IV* }\end{array}$ \\
\hline II & Column, proximal & CTB & $\alpha 6 / \beta 4^{\ddagger}$ & & & $\operatorname{Ln} A, \operatorname{Ln} B 1, \operatorname{Ln} B 2$ \\
\hline III & Column, distal & CTB & $(\alpha 6 / \beta 4)^{\ddagger} \downarrow$ & $\alpha 5 / \beta 1 \uparrow$ & & $\begin{array}{l}\operatorname{Ln} A, \operatorname{Ln} B 1, \operatorname{Ln} B 2 \\
\text { Fn }(A+B+) \uparrow \text { Col IV } \uparrow\end{array}$ \\
\hline IV & Uterine wall & $\begin{array}{l}\text { CTB } \\
\text { Decidual cells }\end{array}$ & $\begin{array}{l}\alpha 1 / \beta 1 \uparrow \\
\alpha 1 / \beta 1 \\
\alpha 6 / \beta 1\end{array}$ & $\begin{array}{l}\alpha 5 / \beta 1 \\
\alpha 5 / \beta 1\end{array}$ & $\begin{array}{l}\alpha 1 / \beta 1 \uparrow \\
\alpha 1 / \beta 1\end{array}$ & $\begin{array}{l}\text { Ln B1, Ln B2, Ln A, } \\
\text { Ln M, Ln B1, Ln B2, } \\
\text { Fn }(A+B+), \text { Col IV, Tn }\end{array}$ \\
\hline
\end{tabular}

${ }^{8} \mathrm{Ln} A, \mathrm{Ln}$ with A chain; $\mathrm{Ln} \mathrm{M}, \mathrm{Ln}$ with merosin variant of the A chain; $\mathrm{Ln} \mathrm{S}, \mathrm{Ln}$ with S variant of the B1 chain. * Polarized distribution at basal surface of CTB layer; ${ }^{\ddagger}$ ligand not firmly established; ( ), expressed at low level; component detected at increased $\uparrow$ or decreased $\downarrow$ levels as compared with previous compartment. 

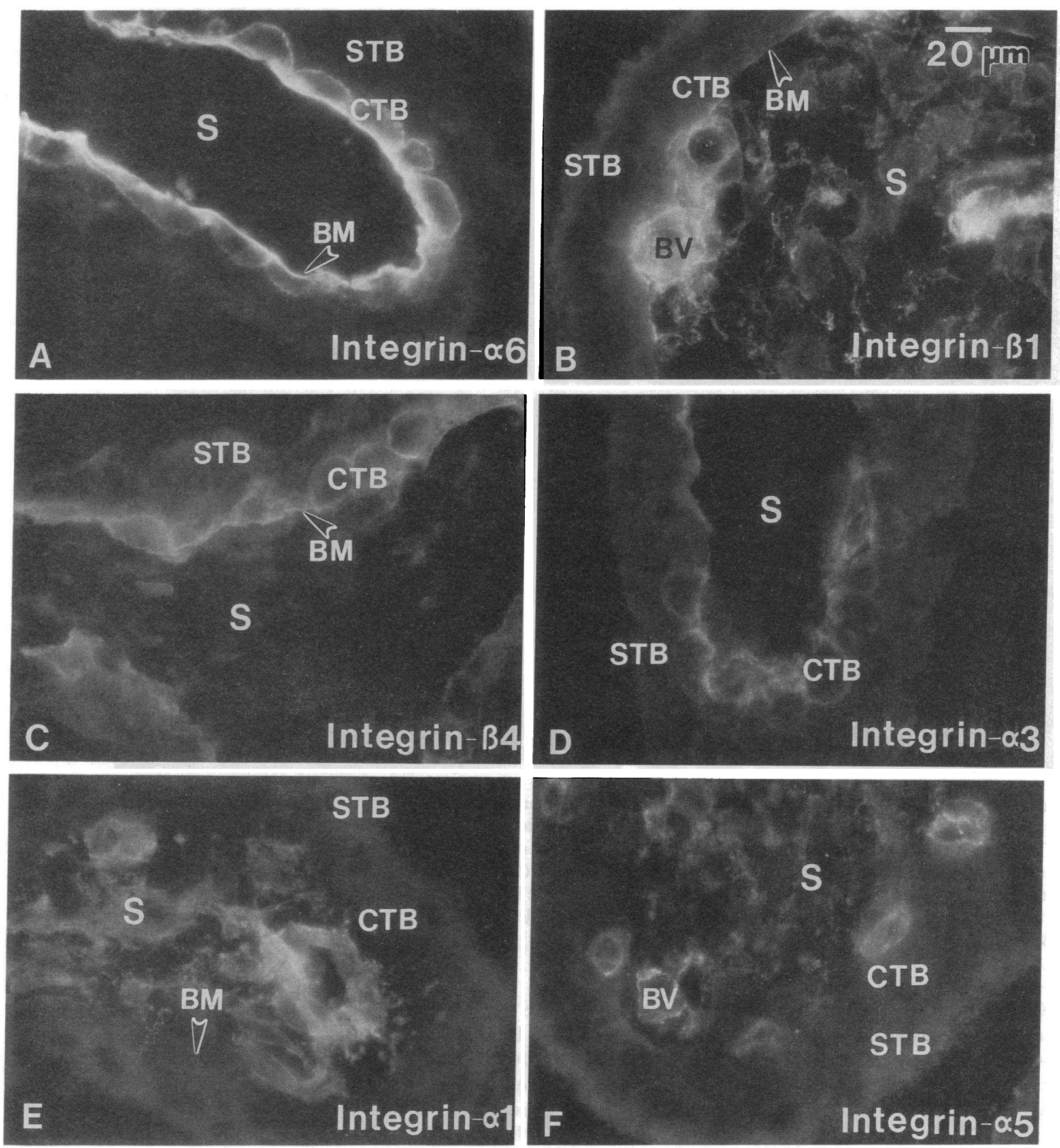

Figure 3. Detection of integrins in floating villi. (A) Anti- $\alpha 6$ stained CTB strongly and exclusively. Staining was enriched at the basal surface, but punctate staining was also present around the lateral and apical borders of CTB. (B) Anti- $\beta 1$ antibody stained all cellular elements of the villus stroma. Staining of villus blood vessels $(B V)$ was particularly strong. Very weak, uniform staining was also detected along the trophoblast BM and over the whole surface of CTB. $(C)$ Anti- $\beta 4$ antibody stained the whole CTB surface, but was enriched basally. (D) Anti- $\alpha 3$ stained CTB in some, but not all, villi. Staining was uniform over the CTB surface. $(E)$ Anti- $\alpha 1$ stained villus stromal cells strongly, but did not stain BM or CTB. $(F)$ Anti- $\alpha 5$ stained cellular elements in the villus stroma and, like anti- $\beta 1$, stained blood vessels $(B V)$ intensely. Staining was absent or barely detectable on the trophoblast BM and CTB.

more, isolated chorionic villus CTB cultured for $12-18 \mathrm{~h}$ stained strongly for both $\mathrm{A}^{+} \mathrm{B}^{+}$Fn and Col IV, indicating their ability to synthesize these molecules (not shown). Staining for the $\alpha 5$ and $\beta 1$ subunits of the Fn receptor was also strongly enhanced in the distal column (Fig. 5, $A$ and $B$ ). No $\alpha 3$ or $\alpha 4$ was detected on column CTB (not shown). Thus $\alpha 5 / \beta 1$ is probably the major integrin $F n$ receptor expressed in this region.
Finally, staining of both the $\alpha 6$ and $\beta 4$ subunits on CTB, while strong in the proximal column, decreased over the remainder of the column (Fig. 5, $C$ and $D$ ) to undetectable levels on CTB that were present in the superficial decidua (Table II). The observation that the distribution patterns of the $\alpha 6$ and $\beta 4$ subunits were very similar and distinct from that of $\beta 1$ suggested that $\alpha 6 / \beta 4$ was the predominant $\alpha 6$-containing complex ex- 

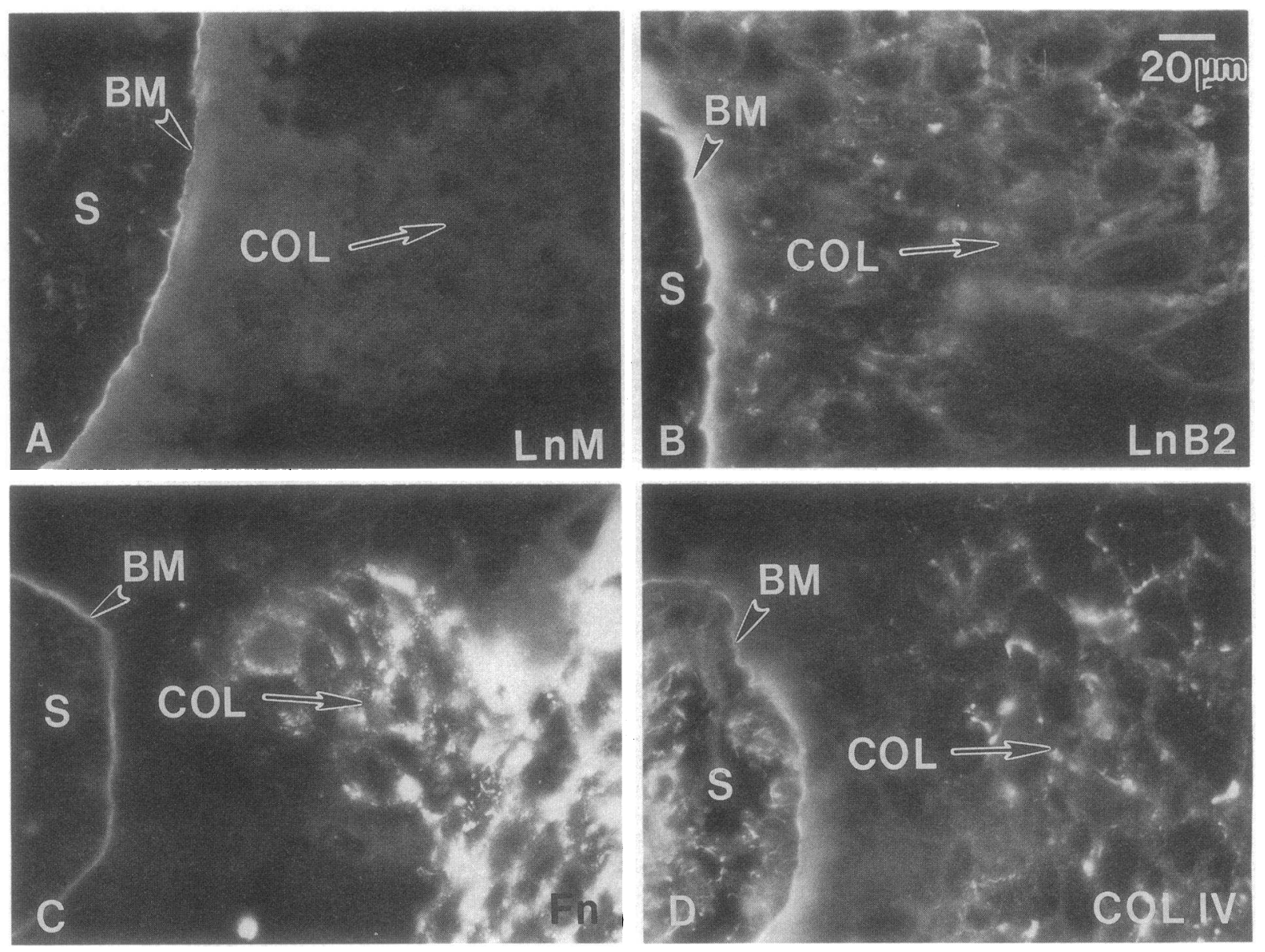

Figure 4. Detection of Ln, Col IV, and Fn in cell columns (zones II and III) of anchoring villi. (A) Merosin (Ln M) was not detected on column CTB, although the antibody stained the anchoring villus trophoblast BM in regions where columns formed. Ln A was detected on the cell surface of column CTB using MAb 11D5/C4. The other anti-Ln A MAb, 4C7, did not detect $\mathrm{Ln} A$ on column CTB, although it detected Ln A in the villus BM (not shown). (B) Anti-Ln B2 MAbs stained column CTB strongly. (C) None of the polyclonal or monoclonal anti-Fn antibodies detected $\mathrm{Fn}$ in the first few layers of the CTB column (the proximal column, zone II). However, Fn staining increased dramatically in the rest of the column (the distal column, zone III). (D) Anti-Col IV staining was barely detectable on proximal column CTB, but was enhanced on distal column CTB.

pressed by CTB in villi and in cell columns, although this does not rule out the presence of some functional $\alpha 6 / \beta 1$, especially in the distal column where $\beta 1$ staining is strong. Taken together, our data suggest that the transition of CTB from the fetal toward the maternal compartment (zones I to III) is marked most notably by a switch in their pattern of integrin expression from $\alpha 6 / \beta 4$ to $\alpha 5 / \beta 1$, and by their synthesis of an extracellular matrix rich in $\mathrm{A}^{+} \mathrm{B}^{+} \mathrm{Fn}$ as well as $\mathrm{Col} \mathrm{IV}, \mathrm{Ln} \mathrm{B} 1$ and $B 2$, and perhaps $\operatorname{Ln} A$.

In the placental bed, CTB column structure is lost and staining patterns suggest that clusters of CTB interact primarily with maternal matrix, via $\alpha 1 / \beta 1$ and $\alpha 5 / \beta 1$ integrins. Within the placental bed (endometrium and myometrium; zone IV) the column structure was lost, and CTB were present as clusters of irregularly shaped cells or as single cells. Placental bed CTB stained for the hormone hPL, a specific marker for differentiated trophoblasts. These CTB appeared to produce a very restricted matrix of their own. Merosin (Fig. 6 A), Ln A (not shown), and s-laminin (not shown) were all undetectable on hPL-positive CTB. Staining for Ln B2 using the D18 MAb (Fig. $6 C$ ) continued to be strong on CTB. However, the Ln B2 MAb 2E8/A11 did not stain CTB in the placental bed, although it, like the D18 Ln B2 MAb, stained maternal cells. Staining for Ln B1 on CTB was weak and variable (not shown). Placental bed CTB also no longer expressed detectable levels of Fn (Fig. 6 $E$ ) or Col IV (not shown) on their cell surfaces. In contrast, the surrounding endometrium and myometrium were rich in Fn $\left(\mathrm{A}^{+} \mathrm{B}^{+}\right.$), Col IV, and $\mathrm{Ln} \mathrm{A}, \mathrm{B} 1$, and B2 (Fig. 6, Table II; see also 28). Thus, within the placental bed, CTB are likely to interact primarily with a matrix associated with maternal cells. CTB displayed yet another distinct repertoire of $\beta 1$ integrins within the placental bed (Fig. 7): $\alpha 1 / \beta 1$ (Fig. $7 A$ ), not detected on CTB in any other location, and $\alpha 5 / \beta 1$ (Fig. $7 C$ ). Other $\beta 1$ integrins $(\alpha 2, \alpha 3, \alpha 4, \alpha 6$ [Fig. $7 \mathrm{E}$ ]) as well as $\beta 4$ were not detected on CTB in the placental bed compartment. The presence on CTB of this combination of $\beta 1$ integrin subunits theoretically gives them the ability to recognize Lns and Col IV (using $\alpha 1 / \beta 1$ ) and Fn (using $\alpha 5 / \beta 1$ ).

Tenascin is expressed in the fetal and maternal stroma at transition points in CTB differentiation. One of the most significant potential regulatory points for CTB differentiation occurs when CTB at specific sites in anchoring villi form multilayered cell columns (Fig. 1, $A$ and $B$ ). The signals that trigger this transition and the accompanying changes in adhesion protein 

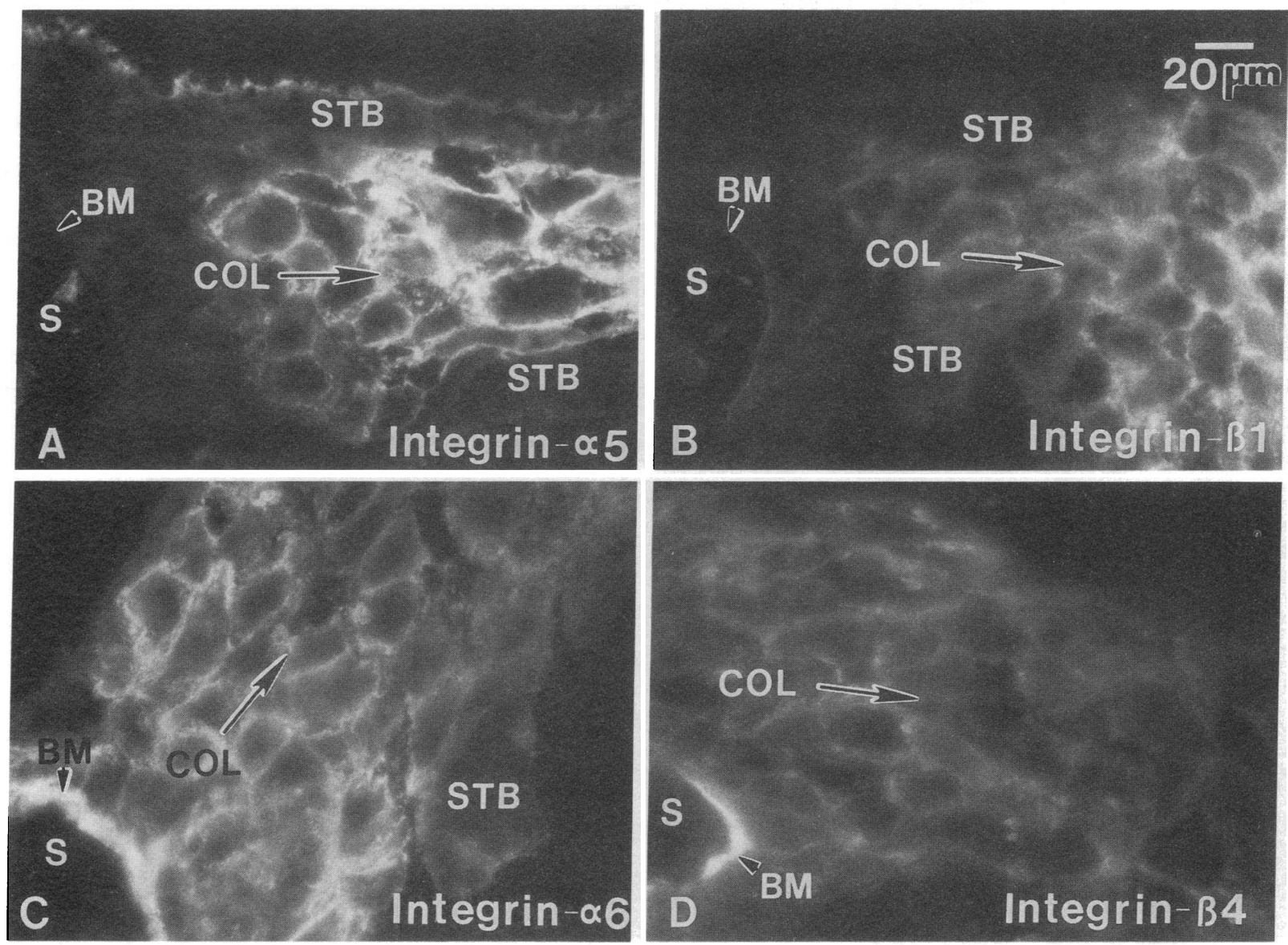

Figure 5. Staining for integrin subunits in cell columns (zones II and III). (A) Anti- $\alpha 5$ and $(B)$ anti- $\beta 1$ staining were barely detectable in the proximal column. Staining for both increased dramatically in the distal column, mimicking the staining patterns of Fn and Col IV. (C) Anti- $\alpha 6$ and $(D)$ anti- $\beta 4$ both stained proximal column CTB strongly, and then decreased over the length of the column.

expression are unknown. One possible clue was suggested by the distribution pattern of the high molecular weight, developmentally regulated ECM component tenascin (Tn). In floating villi, staining for Tn was absent from the stroma beneath the cytokeratin-positive trophoblast layer (Fig. 8, $A$ and $B$ ). In contrast, in the anchoring villus, strong staining for Tn was detected in the stroma immediately subjacent to sites of CTB column initiation (Fig. $8 \mathrm{C}$ ). Tn was not detected on villus CTB. Thus, the Tn distribution was intriguing, as it was the only component detected that distinguished the stromal ECM in the precise region of the anchoring villus where a column formed. Tn was not detected on cytokeratin-positive CTB in columns or in the placental bed. However, it displayed a patchy distribution pattern in the ECM associated with the decidua. Tn also stained discrete arcs at the periphery of some maternal blood vessels, and stained the myometrium strongly and uniformly (Fig. $8 E$ ). These results indicate that $\mathrm{Tn}$ is expressed selectively at stromal sites where transitions in CTB differentiation take place (initiation sites for column formation; decidua, myometrium, and blood vessels of the uterine wall).

\section{Discussion}

Our data represent a comprehensive analysis of the striking changes in the distribution patterns of adhesion receptors and matrix components that take place on CTB in the region of transition between the fetal and maternal compartments of the first trimester placenta. This region recapitulates spatially the differentiation process during which polarized CTB monolayers in anchoring villi first become cohesive, nonpolar cell aggregates and then invade the uterine wall as dispersed cell clusters and single cells $(5,8,9)$. Since a great deal of information exists on the function of the adhesion and matrix molecules we have localized, analyzing the specific repertoire of these molecules present at each stage of CTB differentiation provides insight into the concomitant alterations in CTB behavior.

The polarized CTB epithelium of chorionic villi (zone I) is anchored to the trophoblast $\mathrm{BM}$, which contains several isoforms of $\operatorname{Ln}$ (see also 14), $\mathrm{A}^{+} \mathrm{B}^{+} \mathrm{Fn}$, and Col IV (Table II). Because of their similar staining intensities and basal location, $\alpha 6$ in association with $\beta 4$ appears to be the most important receptor complex mediating CTB interactions with the trophoblast BM. The ligand for $\alpha 6 / \beta 4$ in BM is unclear, but may be a form of $\operatorname{Ln}(29)$. Other reports document its association with hemidesmosomes $(25,30)$. Since weak staining for $\beta 1$ is detected in the trophoblast BM, it is possible that a small amount of $\alpha 6 / \beta 1$ may also be present. This should promote CTB interactions with the long arm of $\operatorname{Ln}$ in the trophoblast $\operatorname{BM}(12,19)$.

CTB differentiation along the invasive pathway is initiated at discrete sites in anchoring villi, as evidenced by the presence 

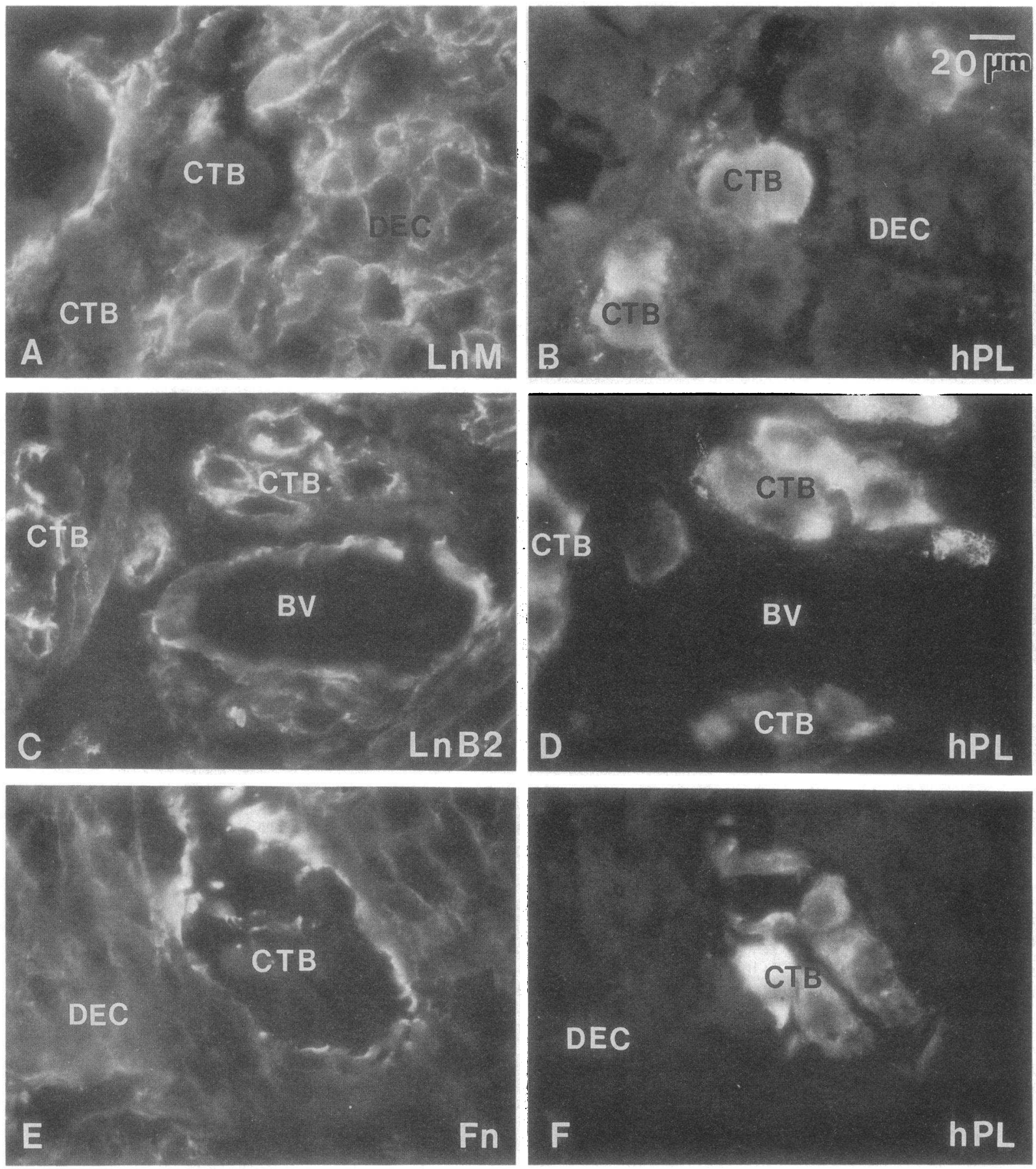

Figure 6. Detection of $\mathrm{Ln}$ and Fn in the uterine placental bed (zone IV). A section of the placental bed stained with $(A)$ anti-merosin $(L n M)$, and $(B)$ anti-hPL. Ln M was not detected on hPL-positive, differentiated CTB that had invaded the placental bed. In contrast, Ln M was expressed widely by maternal cells throughout the placental bed. Anti-Ln A gave the same pattern (not shown). Thus, neither known A-like Ln subunit was detected on placental bed CTB. A section of the placental bed stained with $(C)$ anti-Ln B2 and $(D)$ anti-hPL. Strong Ln B2 staining was detected on both hPL-positive CTB and maternal cells when MAb D18 was used. The anti-Ln B2 MAb 2E8/A11 did not stain placental bed CTB, although maternal cells were stained (not shown). $(E)$ Anti-Fn antibodies did not detect Fn on the surface of placental bed CTB. Strong Fn staining was detected surrounding maternal cells. Polyclonal and domain-specific antibodies gave the same staining pattern. $(F)$ Same section stained with anti-hPL to detect CTB.

of multilayered cell columns in which CTB are no longer polarized. There was no apparent change in the staining patterns of Ln, Fn, or Col IV associated with the trophoblast BM at sites of column initiation. However, Tn was detected in the villus stroma under the BM only at sites of column formation. The nature of Tn's contribution is suggested by its well-documented transient induction in mesenchyme by epithelium, during epithelial-mesenchymal interactions (reviewed in 31 , 32). It is possible that during column formation an analogous signalling process is triggered at or near villus tips in anchoring 

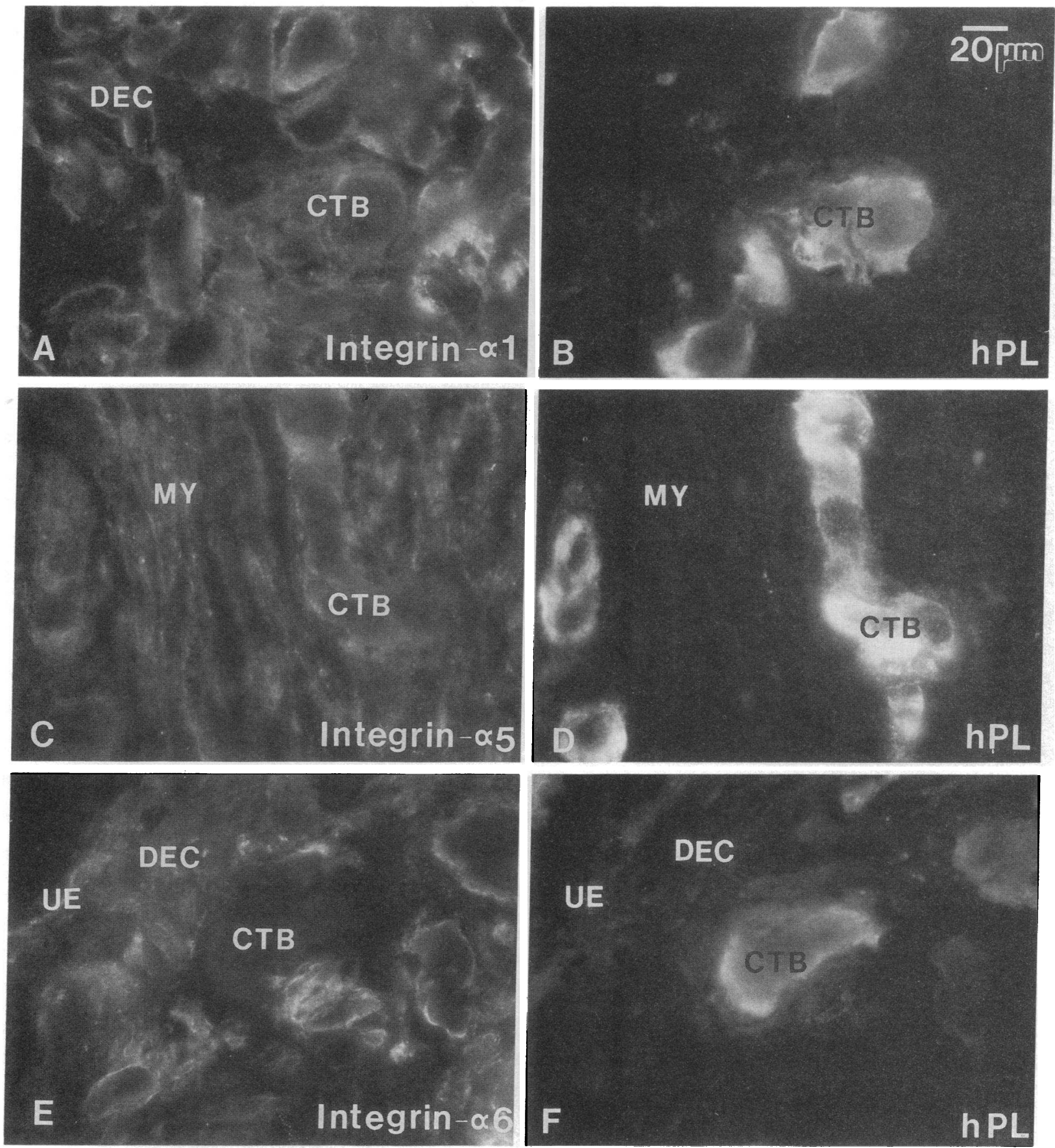

Figure 7. Detection of integrins in the placental bed using double indirect immunofluorescence to stain the same section for an integrin $(A, C, E)$ and $\mathrm{hPL}(B, D, F) .(A)$ Anti- $\alpha 1$ and $(C)$ anti- $\alpha 5$ stained both placental bed CTB and maternal cells. $(E)$ Anti- $\alpha 6$ did not stain placental bed CTB. The $\alpha 6$ subunit was detected on maternal cells throughout the endometrium and myometrium, as well as on the uterine epithelium (UE). Anti- $\beta 4$ staining in the placental bed was restricted to the UE basement membrane (not shown). Thus, $\alpha 6$ in the endometrium and myometrium is associated with $\beta 1$.

villi, causing stromal cells to produce $\mathrm{Tn}$, which then promotes disorganization of the overlying polarized CTB monolayer. This would permit the formation of a cohesive, multilayered column of CTB.

CTB displayed altered patterns of expression of several adhesion and matrix components, both at the outset of column formation (zone II, proximal column) and along the length of the column (zone III, distal column). Fn and the $\alpha 5$ and $\beta 1$ subunits of the $\alpha 5 / \beta 1$ Fn receptor were not detected in the first few layers of the column (zone II). However, staining for all three increased substantially in the distal column. In light of the observation that staining for the $\alpha 6$ and $\beta 4$ subunits was reduced in that area, these data suggest that $\alpha 5 / \beta 1$ interaction with $\mathrm{A}^{+} \mathrm{B}^{+}$Fn of CTB origin is the major CTB-matrix interaction exhibited in zone III. The remaining $\alpha 6 / \beta 4$ and/or $\alpha 6$ in association with $\beta 1$ may also interact with $\mathrm{Ln}$, or with other ECM components present in this region.

Within the placental bed, CTB appeared to lack a cell-asso- 

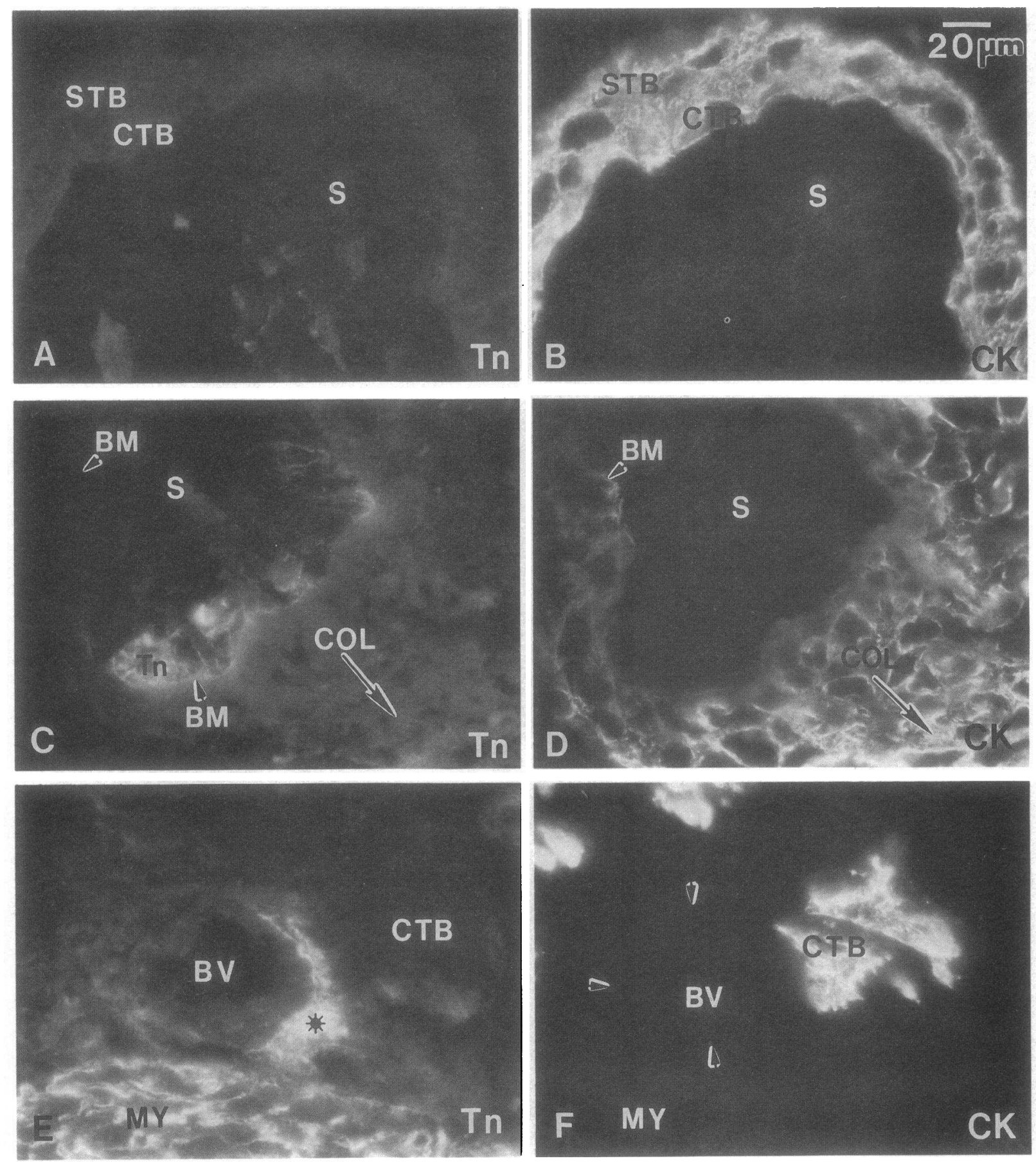

Figure 8. Staining for tenascin $(T n)$ in first trimester placenta. $(A)$ In floating villi, Tn staining was absent in the stroma subjacent to the trophoblast BM. $(B)$ Same section stained with anti-cytokeratin $(C K)$ to mark CTB and STB layers. $(C)$ In anchoring villi, anti-Tn staining was almost exclusively restricted to the villus stroma immediately subjacent to the trophoblast BM in regions of CTB column formation $(C O L)$. $(D)$ Same section stained with anti-CK. $(E)$ In the placental bed, patchy Tn staining was detected in the decidual layer and strong uniform staining was present in the myometrium $(M Y)$. Arcs of strong Tn staining $\left(^{*}\right)$ were frequently detected at the periphery of maternal blood vessels $(B V)$. Anti-Tn did not detect Tn on CTB in any location in the first trimester placenta (compare $E$ with $F$ ).

ciated ECM. Fn and Col IV were no longer detected in association with the CTB surface. In the case of Ln, neither Ln A nor merosin were detected, B1 staining was weak and Ln B2 staining was detected with only one of the two MAbs, raising the possibility that placental bed CTB produce little, if any, Ln. In contrast, the surrounding maternal cell-associated matrix stained with all antibodies against the A, B1, and B2 subunits of
Ln. This pattern of $\mathrm{Ln}$ subunit expression was also observed in fresh-frozen methanol-fixed samples (not shown). Differential expression of Ln A-like and B-like chains has been observed in other developing systems in which cells have undergone changes in polarity, as is the case with differentiating CTB (33, 34). Immunocytochemistry with additional subunit-specific antibodies, in situ hybridization, and a careful search for alter- 
native $\mathrm{Ln}$ isoforms will be required to settle the issue of what kind of $\mathrm{Ln}$, if any, is being made by first trimester placental bed CTB. Placental bed CTB also displayed a distinctive repertoire of integrins: $\beta 1$, but not $\beta 4$, was detected, and the $\alpha$ subunit repertoire was restricted to the $\alpha 1$ and $\alpha 5$ subunits. Thus the predominant interactions of CTB in the placental bed are likely to involve CTB $\alpha 1 / \beta 1$ and $\alpha 5 / \beta 1$ with maternal cell-associated ECM, which is rich in Col IV, Ln, and Fn (28), as well as Tn (Fig. 8).

The striking changes in the repertoire of adhesion receptors detected on differentiated placental bed CTB, combined with exposure to the distinctive maternal ECM, are likely to affect the behavior and gene expression of CTB. For example, by changing their repertoire of $\mathrm{Ln}$ receptors (see Tables I and II), villus CTB and differentiated placental bed CTB might interact with structurally distinct regions of $\operatorname{Ln}(35)$, resulting in distinct cellular responses. In support of this idea are our observations that in JAR choriocarcinoma cells, the $\alpha 1 / \beta 1$ integrin recognizes a site in the cross region of $\operatorname{Ln}(12$; see also 36$)$ whereas $\alpha 6 / \beta 1$ recognizes a site in the structurally distinct Ln long arm $(12,19)$. In a second example, the presence of Tn at sites of column formation and in the decidual/myometrial ECM may also influence CTB motility and invasiveness. As discussed above, Tn expression at selected sites in the villus stroma may play a role in CTB column formation. Data showing that addition of $T n$ to Fn substrates in vitro reduces cell adhesiveness to Fn (37) and mimics the ability of Fn fragments and anti-Fn receptor antibodies to induce metalloproteinase expression in fibroblasts (38) support the idea that Tn could influence cell motility and invasion. Such matrix-induced effects on motility and proteinase expression are likely to be particularly relevant to the transient tumor cell-like behavior of 1st TM CTB (24).

The alterations in distribution patterns of adhesion and matrix molecules on CTB in cell columns and within the uterine wall in vivo fit into a larger picture of CTB differentiation that includes hormones, proteinases, and proteinase inhibitors $(24,39)$. Our studies to determine the role of those components have resulted in the development of an in vitro model in which 1st TM CTB, but not late gestation CTB, aggregate and invade Matrigel. Studies using this model have revealed a critical role for the $92-\mathrm{kD}$ type IV collagenase in CTB invasion (24). Preliminary results indicate that CTB which are invading Matrigel exhibit a repertoire of matrix and adhesion components similar to that reported here for differentiating CTB in vivo (Fitzgerald, M. L., and C. H. Damsky, unpublished experiments). Therefore this model, in conjunction with function-perturbing antibodies against the adhesion molecules that we have now shown to be differentially expressed during CTB differentiation in vivo, will be extremely useful in determining the functional role of these components in trophoblast invasion. These studies also lay the foundation for determining whether abnormal regulation of adhesion or matrix molecule expression is a feature of placental disorders involving insufficient or excessive invasion.

\section{Acknowledgments}

The authors acknowledge the expert assistance of King Chiu and Zhou Yang. The following investigators generously provided antibodies for this study, as itemized in Methods: Drs. Robert Burgeson, Eva Engvall, Steven Kennel, Vera Morhenn, Joshua Sanes, Arnoud Sonnenberg, Elizabeth Wayner, and Luciano Zardi.
This work was supported by grants HD22210, HD22518, and HD8-2903 from the National Institute for Child Health and Human Development.

Note added in proof. Castellucci et al. (42) have suggested that tenascin participates both in proliferation of villous trees and in repair processes in the placenta.

\section{References}

1. Robertson, W. B., I. A. Brosens, and H. G. Dixon. 1981. Maternal blood supply and fetal growth retardation. In Fetal Growth Retardation. F. A. Assche, W. B. Robertson, and M. Renaer, editors. Churchill Livingstone, London. 126138.

2. Hughes, E. C. 1972. Obstetric Gynecologic Terminology. F. A. Davis Co., Philadelphia. 423 pp.

3. Brosens, I., and H. G. Dixon. 1966. Anatomy of the maternal side of the placenta. J. Obstet. Gynaecol. Br. Commonw. 73:357-363.

4. Boyd, J. D., and W. J. Hamilton. 1970. The Human Placenta. Heffer and Sons, Cambridge. 365 pp.

5. Enders, A. C. 1968. Fine structure of anchoring villi of the human placenta. Am. J. Anat. 22:419-452.

6. Enders, A. C. 1976. Cytology of early human implantation. Res. Reprod. $8: 1-2$.

7. Fisher, S. J., T. -Y. Cui, L. Zhang, L. Hartman, K. Grahl, G. -Y. Zhang, J. Tarpey, and C. H. Damsky. 1989. Adhesive and invasive interactions of human cytotrophoblast cells in vitro. J. Cell Biol. 109:891-902.

8. Pijnenborg, R. 1990. Trophoblast invasion and placentation: morphological aspects. Troph. Res. 4:33-50.

9. Kurman, R. J., C. S. Main, and H. -C. Chen. 1984. Intermediate trophoblast: a distinctive form of trophoblast with distinctive morphological, biochemical and functional features. Placenta. 5:349-370.

10. Yeh, I. -T., and R. J. Kurman. 1989. Functional and morphologic expressions of trophoblast. Lab. Invest. 61:1-3.

11. Pijnenborg, R., J. M. Bland, W. B. Robertson, and I. Brosens. 1983. Uteroplacental arterial changes related to interstitial trophoblast migration in early human pregnancy. Placenta. 4:387-414.

12. Hall, D., L. Reichardt, E. Crowley, H. Moezzi, B. Holley, A. Sonnenberg, and C. H. Damsky. 1990. The $\alpha 1 / \beta 1$ and $\alpha 6 / \beta 1$ integrin heterodimers mediate cell attachment to distinct sites on Ln. J. Cell Biol. 110:2175-2184.

13. Leivo, I., and E. Engvall. 1988. Merosin, a protein specific for basement membranes of Schwann cells, striated muscle, and trophoblast, is expressed late in nerve and muscle development. Proc. Natl. Acad. Sci. USA. 85:1544-1548.

14. Engvall, E., D. Earwicker, T. Haaparanta, E. Ruoslahti, and J. R. Sanes. 1990. Distribution and isolation of laminin variants: tissue restricted distribution of heterodimers assembled from five different subunits. Cell Reg. 1:731-740.

15. Sanes, J. R., E. Engvall, R. Butkowski, and D. D. Hunter. 1990. Molecular heterogeneity of basal laminae: isoforms of laminin and collagen IV at the neuromuscular junction and elsewhere. J. Cell Biol. 111:1685-1699.

16. Carnemolla, B., E. Balza, A. Siri, L. Zardi, M. R. Nocitra, A. Bigotti, and P. G. Natali. 1989. A tumor associated fibronectin isoform generated by alternative splicing of messenger RNA precursors. J. Cell Biol. 108:1139-1148.

17. Werb, Z., P. M. Tremble, O. Behrendtsen, E. Crowley, and C. H. Damsky 1989. Signal transduction through the fibronectin receptor induces collagenase stromolysin gene expression. J. Cell Biol. 109:877-889.

18. Sonnenberg, A., H. Daams, M. Van du Vaek, J. Hilkins, and J. Hilgers. 1986. Development of mouse mammary gland: identification of stages in differentiation of luminal and myoepithelial cells using monoclonal antibodies and polyvalent antiserum against keratins. J. Histochem. Cytochem. 34:1037-1046.

19. Sonnenberg, A., C. J. T. Linders, P. W. Modderman, C. H. Damsky, and M. Aumailley. 1990. Integrin recognition of different cell binding fragments of laminin (P1, E3 and E8) and evidence that $\alpha 6 / \beta 1$, but not $\alpha 6 / \beta 4$, functions as a major receptor for E8. J. Cell Biol. 110:2145-2155.

20. Kennel, S. J., L. J. Foote, R. Falcioni, A. Sonnenberg, C. Stringer, C. Crouse, and M. Hemler. 1989. Analysis of the tumor-associated antigen TSP180: identity with $\alpha 6 / \beta 4$ in the integrin superfamily. J. Biol. Chem. 264:1551515521.

21. Morhenn, V., A. B. Schreiber, O. Soriero, W. McMillan, and A. C. Allison. 1985. A monoclonal antibody against basal cells of human epidermis. $J$. Clin. Invest. 76:1978-1983.

22. Hemler, M., F. Sanchez-Madrid, T. Flotte, I. Krensky, S. Burakoff, A. Bahn, T. Springer, and J. Strominger. 1984. Glycoproteins of 210,000 and $130,000 \mathrm{M}$. W. on activated T cells: cell distribution and antigenic relation to components on resting cells and T cell lines. J. Immunol. 132:3011-3018.

23. Wayner, E. A., A. Garcia-Pardo, M. Humphries, J. McDonald, and W. G. Carter. 1989. Identification and characterization of the T-lymphocyte adhesion 
receptor for an alternative cell attachment domain (CS-1) in plasma fibronectin. J. Cell Biol. 111:1321-1330.

24. Librach, C., Z. Werb, M. L. Fitzgerald, K. Chiu, N. Corwin, R. Esteves, D. Grobelny, R. Galardy, C. H. Damsky, and S. J. Fisher. 1991. 92 KDa Type IV collagenase mediates invasion of human cytotrophoblasts. J. Cell Biol. 113:437449.

25. Carter, W. G., P. Kaur, S. G. Gil, P. J. Gahr, and E. A. Wayner. 1990. Distinct functions for $\alpha 3 / \beta 1$ in focal adhesions and $\alpha 6 / \beta 4$ bullous pemphigoid antigen in a new stable anchoring contact (SAC) of keratinocytes: relation to hemidesmosomes. J. Cell Biol. 111:3141-3154.

26. Larjava, H., J. Peltonen, S. Akiyama, H. Gralnik, J. Uitto, and K. M. Yamada. 1990. Novel function for $\beta 1$ integrins in keratinocyte cell-cell interactions. J. Cell Biol. 110:803-815.

27. Hemler, M. E., C. Crouse, and A. Sonnenberg. 1989. Association of the VLA $\alpha 6$ with a novel protein. J. Biol. Chem. 264:6529-6533.

28. Wewer, U. M., M. Faber, L. Liotta, and R. Albrechtsen. 1985. Immunochemical and ultrastructural assessment of the nature of the pericellular basement membrane of human decidual cells. Lab. Invest. 53:624-633.

29. Lotz, M. M., C. A. Korzelius, and A. M. Mercurio. 1990. Human colon carcinoma cells use multiple receptors to adhere to laminin: involvement of $\alpha 6 \beta 4$ and $\alpha 2 \beta 1$ integrins. Cell Reg. 1:249-257.

30. Stepp, M. A., S. Spurr-Michaud, A. Tisdale, J. Elwell, and I. K. Gipson. 1990. $\alpha 6 / \beta 4$ integrin heterodimer is a component of hemidesmosomes. Proc. Natl. Acad. Sci. USA. 87:8970-8974.

31. Erickson, H. P., and M. Bourdon. 1989. Tenascin: an extracellular matrix protein prominent in specialized embryonic tissues and tumor cells. Annu. Rev. Cell Biol. 5:71-92.

32. Ekblom, P., and E. Aufderheide. 1989. Stimulation of tenascin expression in mesenchyme by epithelial-mesenchyme interactions. Int. J. Dev. Biol. 33:7179.
33. Klein, G., M. Langegger, R. Timpl, and P. Ekblom. 1988. Role of laminin A chain in epithelial cell polarity. Cell. 55:331-341.

34. Klein, G., M. Ekblom, L. Fecker, R. Timpl, and P. Ekblom. 1990. Differential expression of laminin A and B chains during development of embryonic mouse organs. Development (Camb.). 110:823-838.

35. Beck, K., I. Hunter, and J. Engel. 1989. Structure and function of laminin: anatomy of a multidomain glycoprotein. FASEB (Fed. Am. Soc. Exp. Biol.) J. 3:148-160.

36. Tomaselli, K. J., D. E. Hall, L. A. Flier, K. R. Gehlsen, D. C. Turner, S. Carbonetto, and L. Reichardt. 1991. A neuronal cell line (PC12) expresses two $\beta 1$-class integrins, $\alpha 1 / \beta 1$ and $\alpha 3 / \beta 1$, that recognize different neurite outgrowthpromoting domains in Ln. Neuron. 5:651-662.

37. Chiquet-Ehrismann, R., P. Kalla, S. G. Pearson, K. Beck, and M. Chiquet. 1988. Tenascin interferes with fibronectin action. Cell. 53:383-390.

38. Werb, Z., P. Tremble, and C. H. Damsky. 1990. Regulation of extracellular matrix degradation by cell-extracellular matrix interactions. Cell Differ. Dev. 32:299-306.

39. Feinberg, R. F., K. Lee-Chuan, J. E. Haimowitz, J. T. Queenan, W. TzeChein, J. F. Strauss, and H. J. Kliman. 1989. Plasminogen activator inhibitor types 1 and 2 in human trophoblast: PAI-1 is an immunochemical marker of invading trophoblast. Lab. Invest. 61:20-27.

40. Albeda, S. M., and C. A. Buck. 1990. Integrins and other cell adhesion molecules. FASEB (Fed. Am. Soc. Exp. Biol.) J. 4:2869-2880.

41. Gehlsen, K., K. Dickerson, W. S. Argraves, E. Engvall, and E. Ruoslahti. 1989. Subunit structure of a laminin-binding integrin and localization of its binding site on laminin. J. Biol. Chem. 264:19034-19038.

42. Castellucci, M., I. Classen-Linke, J. Mühlhauser, P. Kaufmann, L. Zardi, and R. Chiquet-Ehrismann. 1991. The human placenta: a model for tenascin expression. Histochemistry. 95:449-458. 